\title{
Analysis of control factors and surface integrity during wire- EDM of Inconel 718 alloy using T-GRA approach
}

\author{
Md Ehsan Asgar' ${ }^{1}$, Ajay Kumar Singh Singholi² \\ 1USICT, Guru Gobind Singh Indraprastha University, New Delhi, India -110078 \\ 2Professor, USAR, Guru Gobind Singh Indraprastha University East Campus, New \\ Delhi, India -110020 \\ Email: ajay.igit@gmail.com \\ Correspondence Author: asgarehsan@gmail.com
}

Received September 15, 2021; Revised October 17, 2021; Accepted November 19, 2021

\begin{abstract}
In today's competitive modern manufacturing sectors, there is a vital need of utter precision and rigorous processing using various manufacturing approaches that directly influences the cost and processing duration of mechanized materials in addition to the consistency of the finished products. Therefore, it's essential to figure out the required output by adjusting the control factors of any machining techniques which resulted in optimal values of the desired outcome. In this study, machining evaluation and process optimization is carried out on volumetric extraction of material namely material removal rate (MRR), kerf obtained during the machining $\left(\mathrm{K}_{\mathrm{W}}\right)$ and surface roughness (SR) of Inconel 718 superalloy during CNC controlled wire- electrical discharge machining. Four controllable factors- pulse interval, wire speed, pulse duration and peak current are considered to investigate the influence on performance measures. Taguchi's $\mathrm{L}_{16}$ has been used to construct the set of experiments before physical experimental runs and most influencing factors have been evaluated using ANOVA. SEM images and EDXS analysis have been resorted to examine the morphology of Inconel 718. These findings assist in identifying the topography of the machined surface. Further, the optimum integration has been obtained for the best yield and recorded using grey relational analysis integrated with Taguchi's technique (T-GRA). The unfamiliarity of the work is based on consideration of zinc coated thin wire electrode and Taguchi-Grey combined approach of modelling with four levels of experimental design.
\end{abstract}

Keywords: Wire-EDM, Inconel 718, ANOVA, T-GRA, Scanning Electron Microscopy

\section{INTRODUCTION}

Recently, technology based advancement has provided an opportunity for new industrial materials with properties that allow them to be used under harsh operating conditions, which include high temperatures, hostile 
chemical environments, variable loads and others. This type of conditions exist in industrial gas turbines, nuclear power stations, space industry, submarines, equipment for power generators or installations in the chemical industry. Among Ni- Cr based alloys, Inconel 718 is widely used in the manufacturing of industrial turbine engine subsystems which includes blades, combustors and shells; nuclear stations equipment such as reactors and pumps; aircraft and submarines structural equipment; medical devices; dies, casing and heat treating tools [1], [2]. However, Inconel 718 constitute a significant hindrance during conventional machining operations owing to its thermal conductivity, higher work hardening properties, occurrence of abrasives in superalloy, hot-hardness, chemical affection to tool materials and built-up edge formations etc. [3]-[8] Therefore, nonconventional machining operations are preferred.

\section{RELATED WORKS}

Wire-EDM is among the quite important and often used nonconventional thermoelectric technique in the manufacturing sectors due to its ability to create three dimensional complex shape and geometry using bare or coated thin wires [9]-[11]. In the literature, the performance and behaviour of wire-EDM for emerging materials are well established. In general, wire-EDM's machining efficiency is predominantly affected by a combination of characteristics of wire electrode, properties of material, pulse generator system, machine automation system and dielectric fluid flushing technique. Various scientific research and studies have been recorded in the last decades on the machining of materials such as alloys, superalloys and composites using wire-EDM, but limited data available concerning the wireEDM of Inconel 718 with thin coated wire electrode. The impact of new form of $\mathrm{Cu}-\mathrm{SiC}$ electrode for wire-EDM investigated [12] and examine the efficiency of material removal and the surface finishing, among others. As a result, the cutting efficiency increased by 16 percent while roughness $\left(R_{a}\right)$ decreased by around 17 percent on an average. The effect of the control factors of wire-EDM on micro-hardened machined surface of Inconel 617 were examined [13], and stated that many visible micro-cracks developed with increase in current and pulse duration. Simultaneously, the microhardness also increases. The effects of surface quality versus discharge energy are presented [14] and SR for parallel and perpendicular wire directions is shown to be similar and by reducing the discharge energy, its average result can be considerably lowered. The surface structure was compared and recorded white layers and non-uniform confined micro voids with higher discharge energy. Experimental analysis carried out to examine the significant factor in wire-EDM that led to the existence of thick recast layer with 5 to $9 \mu \mathrm{m}$ thickness in Inconel superalloys [15]. Some findings concerning the effect of machining methods on surface morphology and stereo-metric surface parameters in wire-EDM of hard machined materials which also include Inconel alloys, are discussed [16]. Simultaneously, several 
studies can be reported in literature that discusses the challenges correlated with precision machining of different materials with wire-EDM [17]. The findings of magnesium alloy in view of efficient machining operation with different facets of the performance and reliability of the magnesium alloy are discussed using wire-EDM [18], [19]. The findings of an experimental study on the selection of processing conditions that decide performance of wireEDM using aluminium alloy and the optimization abilities of some output responses in wire-EDM of reinforced ZC63 metal matrix composite are discussed [20], [21]. Experimental investigation of performance measures using wire-EDM for alumium alloy-7017 and rolled homogeneous armor (RHA) steel shows favourable value [22]. The multi-response optimization of control factors has been extended further [23]-[25].

\section{ORIGINALITY}

It is clear from the literature report that very less investigation carried out in the machining of Inconel 718 using zn-coated brass wire. In wire-EDM technique, MRR, $\mathrm{K}_{\mathrm{w}}$ and SR are major aspects regarding the performance improvement. Therefore, multi-response optimization has been executed for selected performance measures.

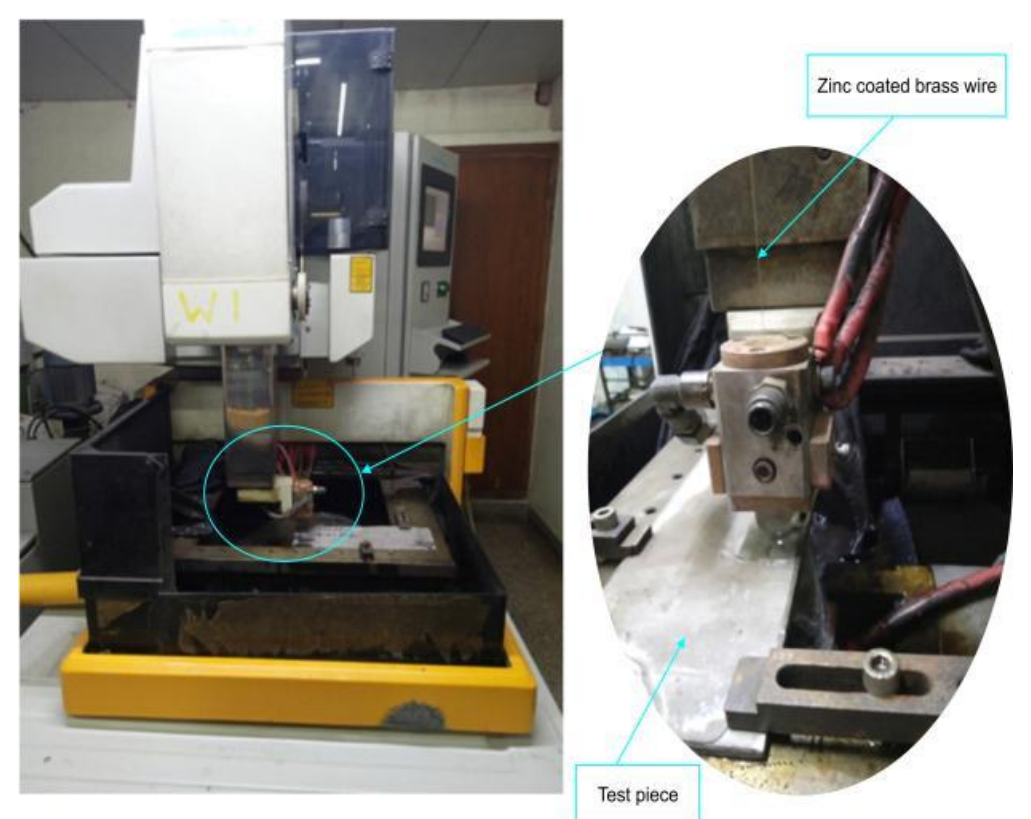

Figure 1. CNC controlled wire EDM experimental setup

The primary objective of this study is to evaluate the impact of control factors in wire-EDM of Inconel 718 material and to identify the optimal condition by adjusting the factors using T-GRA approach for performance gains. Further, SEM images and EDXS analysis have been resorted to examine the surface morphology of Inconel 718. This finding assists in identifying the microstructure changes, material transfer, and compound formation after the machining process. 


\section{SYSTEM DESIGN}

\subsection{Equipments setup and measurement}

In an attempt to conduct the experimental test, Electronica Sprintcut (Elpuls 40) wire electric discharge machine is used in which axial motion in $\mathrm{Z}$-axis, $\mathrm{Y}$-axis and $\mathrm{X}$-axis is controlled by computerized numerically controlled (CNC) mechanism as depicted, Figure 1. A cylindrical coated brass wire with diameter of 0.25 millimetres has handled as an electrode in this analysis. A plate made from a nickel-chromium alloy Inconel 718 (certified by Spectro Analytical Labs Ltd, Greater Noida, India) is considered as a test piece for the experimental study whose mechanical properties and percentage of elements (determined using IS-228-1987/SOP-CHE-00-XRF Spectrometer/SOP-CHE-00-ICP test method) are arranged and depicted in Table 1 and Table 2.

Table 1. Attributes of Inconel 718

\begin{tabular}{|c|c|c|}
\hline $\begin{array}{c}\text { Mechanical /Physical } \\
\text { attribute }\end{array}$ & Count & Units \\
\hline Hardness & 84.6 & HRB \\
\hline Density & 8.2 & $\mathrm{gm} / \mathrm{CC}$ \\
\hline Melting Range & $1260-1330$ & ${ }^{\circ} \mathrm{C}$ \\
\hline
\end{tabular}

Table 2. Percentage composition of Inconel 718

\begin{tabular}{|c|c|c|c|c|c|}
\hline Elements & Nickel & Chromium & Niobium & Molybdenum & Titanium \\
\hline Symbol & $\mathrm{Ni}$ & $\mathrm{Cr}$ & $\mathrm{Nb}$ & $\mathrm{Mo}$ & $\mathrm{Ti}$ \\
\hline Weight \% & 52.91 & 18.29 & 4.79 & 2.82 & 0.9 \\
\hline Elements & $\mathrm{Silicon}$ & Manganese & Cobalt & Carbon & Phosphorus \\
\hline Symbol & $\mathrm{Si}$ & $\mathrm{Mn}$ & $\mathrm{Co}$ & $\mathrm{C}$ & $\mathrm{P}$ \\
\hline Weight \% & 0.22 & 0.2 & 0.2 & 0.06 & 0.01 \\
\hline
\end{tabular}

Initially, the material was a rectangular plate and cut into the pieces of $15 \times 15 \times 5$ (millimetre). Due to comparatively good dielectric strength [26], de-ionized water is exploited as a dielectric liquid in this study. Dielectric flow rate is considered as a noise factor in this experimental analysis.

\subsection{Design of Experiments (DOE) and factors}

A mathematical modelling and statistical approach for organizing the correlation among the various other variables influencing a process is known as DOE. With the aim to achieve the optimum conditions, DOE is an approach that restricts the number of experiments for conducting the test. This investigation is concerned with experimental design, and planned according to L16 orthogonal array design of experiments in order to obtain the results using Minitab( ${ }^{(\mathrm{R})}$-16.1.1 software. Four controllable factors were selected (four levels for each factor) to conduct sixteen experiments with two repeats and then taking their average to get the final count of performance measures.

The most efficient use of the wire-EDM requires careful selection of machine settings. Wire-EDM is a complex system that may be influenced by a wide range of characteristics and other variables. However, Pulse duration, 
pulse interval, peak current and wire speed are most influencing control factors in getting higher accuracy with minimum cost. Peak current is a term used to characterize the maximum current generated during cutting. The discharge energy grows proportionally to the peak current and it grows till the predetermined limit with each pulse time. MRR will be improved with higher currents, but surface quality will be sacrificed. The selected variable factors with their levels are depicted in Table 3. The variations in the value of control factors have been decided as consequences of literature, trial runs and considering the other constraint of wire-EDM to avoid the wire breakage and obtrusion of the machining process.

Table 3. Variable control factor with levels

\begin{tabular}{|c|c|c|c|c|c|c|}
\hline \multirow{2}{*}{ Factors } & \multirow{2}{*}{ Units } & \multirow{2}{*}{ Notations } & \multicolumn{5}{|c|}{ Levels } \\
\cline { 4 - 7 } & & & $\mathbf{1}$ & $\mathbf{2}$ & $\mathbf{3}$ & $\mathbf{4}$ \\
\hline Pulse duration & $\mu \mathrm{s}$ & $\mathrm{T}_{\text {on }}$ & 104 & 107 & 110 & 113 \\
\hline Pulse interval & $\mu \mathrm{s}$ & $\mathrm{T}_{\text {off }}$ & 50 & 52 & 54 & 56 \\
\hline Peak Current & $\mathrm{A}$ & $\mathrm{I}_{\mathrm{p}}$ & 10 & 11 & 12 & 13 \\
\hline Wire Speed & $\mathrm{m} / \mathrm{min}$ & $\mathrm{U}_{\mathrm{w}}$ & 1 & 2 & 3 & 4 \\
\hline
\end{tabular}

Other factors that could influence the performance measures are tabulated and shown in Table 4 and were kept invariable throughout the all sixteen experiments.

Table 4. Invariable machining factor in experiment

\begin{tabular}{|c|c|c|}
\hline Constant factor & Value & Unit \\
\hline Dielectric fluid & De-ionized water & $-\cdot-----$ \\
\hline Dielectric temperature & $21 \pm 1$ & oC \\
\hline Wire Tension & 9 & $\mathrm{~N}$ \\
\hline Servo voltage & 20 & $\mathrm{~V}$ \\
\hline Diameter of wire & 0.25 & $\mathrm{Mm}$ \\
\hline Electrode material & Zn coated brass wire & $-\cdot-----$ \\
\hline Servo feed & 2100 & Machine unit \\
\hline
\end{tabular}

MRR can be estimated as the fraction of volumetric depletion of the test piece to the processing time. The estimation of volumetric reduction of the test piece can be defined using mass-density relation. Therefore, the MRR is calculated using loss in mass criteria function and can be measured by Equation 1:

$$
M R R=\frac{\text { mass reduction in test piece }(\mathrm{gm})}{\text { density of workpiece }\left(\frac{\mathrm{gm}}{\mathrm{mm}^{3}}\right) \times \text { processing time }(\mathrm{min})}
$$

After each run of experiments, the test piece were weighted prior to the machining on a digital weighing balance machine to calculate the mass reduction and used stopwatch to measure the processing time. The value of $\mathrm{Kw}$ was estimated using digital microscope and observed at three locations and then average of measured value was taken for analysis. With the aim to check the SR, measurement of central line average ( $\mathrm{Ra}$ ) were used and measured by using roughness tester ZEISS \& ACCT, SURFCOM FLEX-50A. 
The scanning electron microscopy (SEM) was used to get the microscopic impressions of selected surfaces and energy dispersive x-ray spectroscopy (EDXS) were also conducted to figure out the presence of elements and phases of machined surface.

\subsection{GRA}

The grey relational analysis (GRA) has been practised to optimize the multiple performances. It provides a functional solution to the complexity, multiple inputs and isolated data problems based on grey theory [27]. Since the wire-EDM process is of a multi-faceted nature, the GRA is therefore adopted for the multi-response optimization to optimize the performance measures. Grey theory imparts complete information and represents the known data by black, while insufficient and unidentified information are characterized by white. Grey relation denotes discrete, insufficient, and unpredicted data, and grey relational theory denotes a relationship with complete details and information. The steps involved in GRA [28] shown through flowchart depicted in Figure 2.

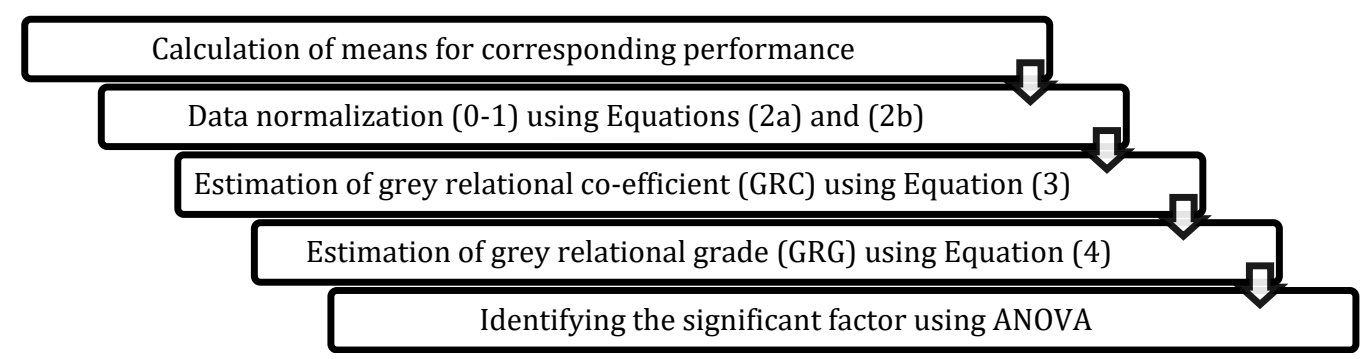

Figure 2. Flowchart involved in GRA

Higher the better for calculation of MRR

$$
z_{i}^{*}(k)=\frac{z_{i}^{o}(k)-\min z_{i}^{o}(k)}{\max z_{i}^{o}(k)-\min z_{i}^{o}(k)}
$$

Lower the better for calculation of Kw and SR.

$$
z_{i}^{*}(k)=\frac{\max z_{i}^{o}(k)-z_{i}^{o}(k)}{\max z_{i}^{o}(k)-\min z_{i}^{o}(k)}
$$

Where $z_{i}^{*}(\mathrm{k})$ is the measured string, $z_{i}^{o}(\mathrm{k})$ is the row string, where max $z_{i}^{o}(\mathrm{k})$ is the larger count of $z_{i}^{o}(\mathrm{k}), \min z_{i}^{o}(\mathrm{k})$ is the smaller count of $z_{i}^{o}(\mathrm{k})$ with $\mathrm{i}=1,2, \ldots \ldots ., \mathrm{m}$ and $\mathrm{k}=1,2, \ldots \ldots . ., \mathrm{n}$ with $\mathrm{m}=16$ and $\mathrm{n}=3$,

To understand the interaction between best and mean values, the GRC is calculated as follows:

$$
£(k)=\frac{\Delta \min +\delta \Delta \max }{\Delta o i(k)+\delta \Delta \max }
$$

Where $\Delta o i(k)$ shows the deviation sequence from normalized data from unity and can be calculated as:

$\Delta \mathrm{oi}(\mathrm{k})=\left|1-\mathrm{z}_{\mathrm{i}}^{*}(\mathrm{k})\right|, \quad \delta$ is the distinguishing co-efficient and usually taken as 0.5 .

The GRG is determined using the following equation by assigning equal weight to all performance measures:

$$
G R G=1 / n \sum_{k=1}^{n} £(k)
$$

Where $E$ is the respective GRC for the performance measures. 


\section{EXPERIMENT AND ANALYSIS}

The investigational performance central value and signal to noise (S/N) ratio of MRR, Kw and SR correspond to all sixteen experimental runs are depicted in Table 5.

Table 5. Experimental value of process performance using $\mathrm{L}_{16} \mathrm{OA}$ with four factors

\begin{tabular}{|c|c|c|c|c|c|c|c|c|c|c|}
\hline $\begin{array}{c}\text { Ex } \\
\text { p. } \\
\text { No. }\end{array}$ & $\begin{array}{c}T_{\text {on }} \\
(\mu \mathrm{S} \\
)\end{array}$ & $\begin{array}{c}T_{\text {off }} \\
(\mu s \\
)\end{array}$ & $\begin{array}{c}I_{p} \\
\text { (A) }\end{array}$ & $\begin{array}{l}U_{w} \\
(\mathrm{~m} \\
/ \mathrm{m} \\
\text { in) }\end{array}$ & $\begin{array}{l}\text { MRR } \\
\left(\mathrm{mm}^{3}\right. \\
\left./ \mathrm{min}^{2}\right)\end{array}$ & $\begin{array}{c}\mathbf{K}_{\mathrm{w}} \\
(\mathbf{m m})\end{array}$ & $\begin{array}{c}\text { SR } \\
(\mu \mathrm{m})\end{array}$ & $\begin{array}{r}\text { S/N } \\
\text { MRR }\end{array}$ & $\begin{array}{c}\mathbf{S} / \mathbf{N} \\
\mathbf{K}_{\mathbf{w}}\end{array}$ & $\begin{array}{l}\text { S/N } \\
\text { SR }\end{array}$ \\
\hline 1 & 1 & 1 & 1 & 1 & 1.092 & 0.317 & 0.423 & 0.764 & 9.979 & 7.473 \\
\hline 2 & 1 & 2 & 2 & 2 & 1.842 & 0.322 & 0.481 & 5.306 & 9.843 & 6.357 \\
\hline 3 & 1 & 3 & 3 & 3 & 2.047 & 0.357 & 0.471 & 6.222 & 8.947 & 6.540 \\
\hline 4 & 1 & 4 & 4 & 4 & 2.745 & 0.398 & 0.481 & 8.771 & 8.002 & 6.357 \\
\hline 5 & 2 & 1 & 2 & 3 & 1.877 & 0.350 & 0.587 & 5.469 & 9.119 & 4.627 \\
\hline 6 & 2 & 2 & 1 & 4 & 1.556 & 0.368 & 0.537 & 3.840 & 8.683 & 5.401 \\
\hline 7 & 2 & 3 & 4 & 1 & 2.290 & 0.358 & 0.542 & 7.197 & 8.922 & 5.320 \\
\hline 8 & 2 & 4 & 3 & 2 & 2.477 & 0.375 & 0.546 & 7.879 & 8.519 & 5.256 \\
\hline 9 & 3 & 1 & 3 & 4 & 2.694 & 0.376 & 0.721 & 8.608 & 8.496 & 2.841 \\
\hline 10 & 3 & 2 & 4 & 3 & 2.616 & 0.372 & 0.696 & 8.353 & 8.589 & 3.148 \\
\hline 11 & 3 & 3 & 1 & 2 & 1.630 & 0.349 & 0.627 & 4.244 & 9.143 & 4.055 \\
\hline 12 & 3 & 4 & 2 & 1 & 2.420 & 0.375 & 0.584 & 7.676 & 8.519 & 4.672 \\
\hline 13 & 4 & 1 & 4 & 2 & 2.925 & 0.365 & 0.802 & 9.323 & 8.754 & 1.917 \\
\hline 14 & 4 & 2 & 3 & 1 & 2.797 & 0.357 & 0.717 & 8.934 & 8.947 & 2.890 \\
\hline 15 & 4 & 3 & 2 & 4 & 3.073 & 0.402 & 0.692 & 9.751 & 7.915 & 3.198 \\
\hline 16 & 4 & 4 & 1 & 3 & 2.532 & 0.411 & 0.671 & 8.069 & 7.723 & 3.466 \\
\hline
\end{tabular}

\subsection{Evaluation of MRR}

With the aim of examine the influence of control factors, an ANOVA has been conducted and results corresponding to MRR depicted in Table 6.

Table 6. ANOVA for MRR

\begin{tabular}{|c|c|c|c|c|c|c|c|}
\hline Source & *DF & *Seq SS & *Adj SS & *Adj MS & *F & *P & \% \\
\hline Ton & 3 & 1.92842 & 1.92842 & 0.642805 & 72.85 & 0.003 & 41.02 \\
\hline Toff & 3 & 0.37285 & 0.37285 & 0.124283 & 14.08 & 0.028 & 7.93 \\
\hline Ip & 3 & 2.06528 & 2.06528 & 0.688425 & 78.02 & 0.002 & 43.94 \\
\hline Uw & 3 & 0.30714 & 0.30714 & 0.102379 & 11.60 & 0.037 & 5.63 \\
\hline $\begin{array}{c}\text { Residual } \\
\text { Errors }\end{array}$ & 3 & 0.02647 & 0.02647 & 0.008824 & & & \\
\hline Total & 15 & 4.70015 & & & & & \\
\hline S = 0.09394 & R-Sq $=99.4 \% \quad$ R-Sq(adj) $=97.2 \%$ & & \\
\hline
\end{tabular}

*DF - Degree of freedom; Seq. SS -Sum of Squares (Sequential); Adj MS - Mean Square (Adjusted); $F-F$ value (At 95\% confidence interval); $p-p$ value.

The results from ANOVA interpreted that peak current is the most influencing factor accounting for $43.94 \%$ of the contribution, followed by pulse duration. The pulse interval and wire speed is less influencing factors for extraction of material from the surface. Figure 3 shows graphs depicting 
the impact of control factors on MRR with response values, which indicate that higher material extraction from the surface with increase in peak current, pulse duration and pulse interval. This may be for the reason that as peak current rises, the discharge energy from the spark generated amongst the wire electrode and the test piece rises as well. This energy raises the temperature, which contribute to higher extraction of material from surface.

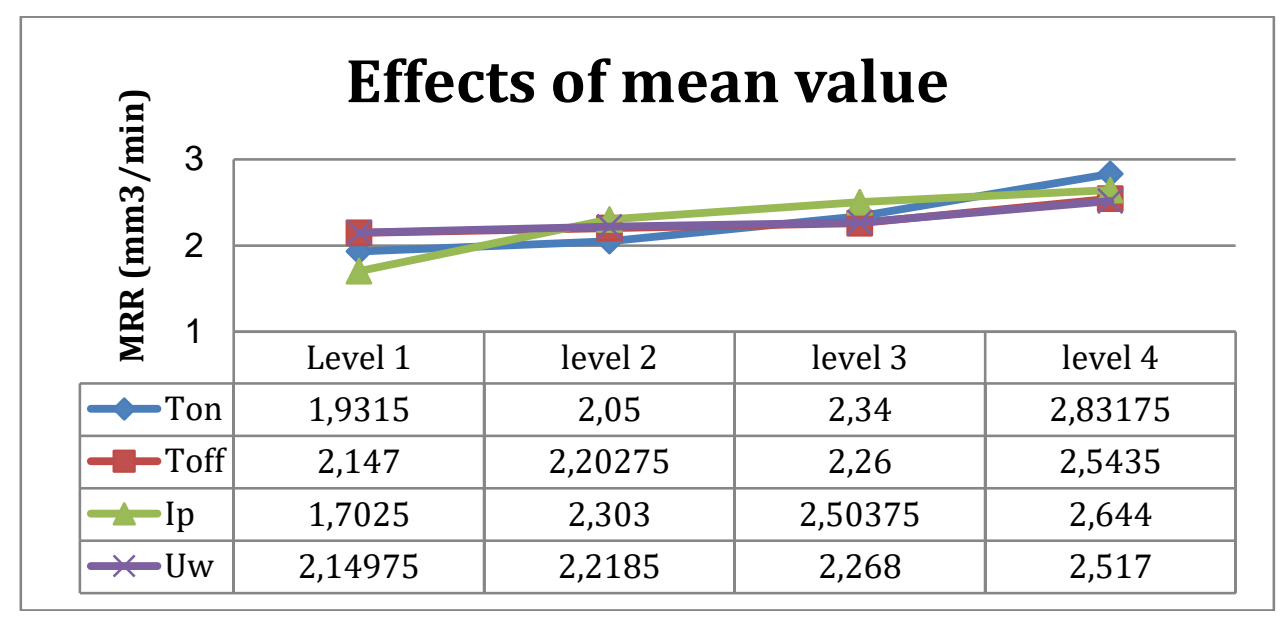

Figure 3. Effect of selected control factors at different levels for MRR

Graph also depicts that corresponding value of MRR increases with the levels of pulse duration and interval. This may be for the reason that considerable amount of heat energy generated between wire electrode and test piece due to higher spark, which leads to faster erosion contributes to higher material removal [29], [30].

\subsection{Evaluation of $\mathrm{Kw}$}

In order to examine the influence of control factors, an ANOVA analysis has been conducted and results corresponding to Kw depicted in Table 7.

Table 7. ANOVA for $\mathrm{K}_{\mathrm{W}}$

\begin{tabular}{|c|c|c|c|c|c|c|c|}
\hline Source & DF & Seq SS & Adj SS & Adj MS & F & P & \% \\
\hline Ton & 3 & 0.002543 & 0.002543 & 0.000848 & 92.45 & 0.002 & 26.06 \\
\hline Toff & 3 & 0.003547 & 0.003547 & 0.001182 & 128.96 & 0.001 & 36.36 \\
\hline Ip & 3 & 0.000356 & 0.000356 & 0.000119 & 12.95 & 0.032 & 3.64 \\
\hline Uw & 3 & 0.003283 & 0.003283 & 0.001094 & 119.36 & 0.001 & 33.65 \\
\hline $\begin{array}{c}\text { Residual } \\
\text { Errors }\end{array}$ & 3 & 0.000028 & 0.000028 & 0.000009 & & & \\
\hline Total & 15 & 0.009755 & & & & & \\
\hline S = 0.003028 R-Sq $99.7 \%$ R-Sq(adj) $=98.6 \%$ & & & \\
\hline
\end{tabular}

The results from ANOVA interpreted that pulse interval is the uttermost influencing factor accounting for $36.36 \%$ of the contribution, followed by wire speed and pulse duration. Figure 4 illustrates graphs depicting the impact of control factors on $\mathrm{Kw}$ with response values, which indicate that $\mathrm{K}_{\mathrm{w}}$ increases with increase in current, pulse duration and pulse interval as well. This may be for the reason that increased pulse duration leads to longer 
spark and large ionization incorporation with dielectric fluid, causes higher chips removal from the surface. As a result, the width increases in accordance with the chips removal from the surface. Graph also indicate that the value of $\mathrm{Kw}$ increases with levels of peak current for the reason that increased intensity of spark attributes to high spark energy generation caused by quantum electrons discharged from wire hitting with the dielectric fluid contributing in large ionization [31], [32]. High intensity spark and large ionization causes the widening of the kerf when considerable amount of ions strike with the test piece.

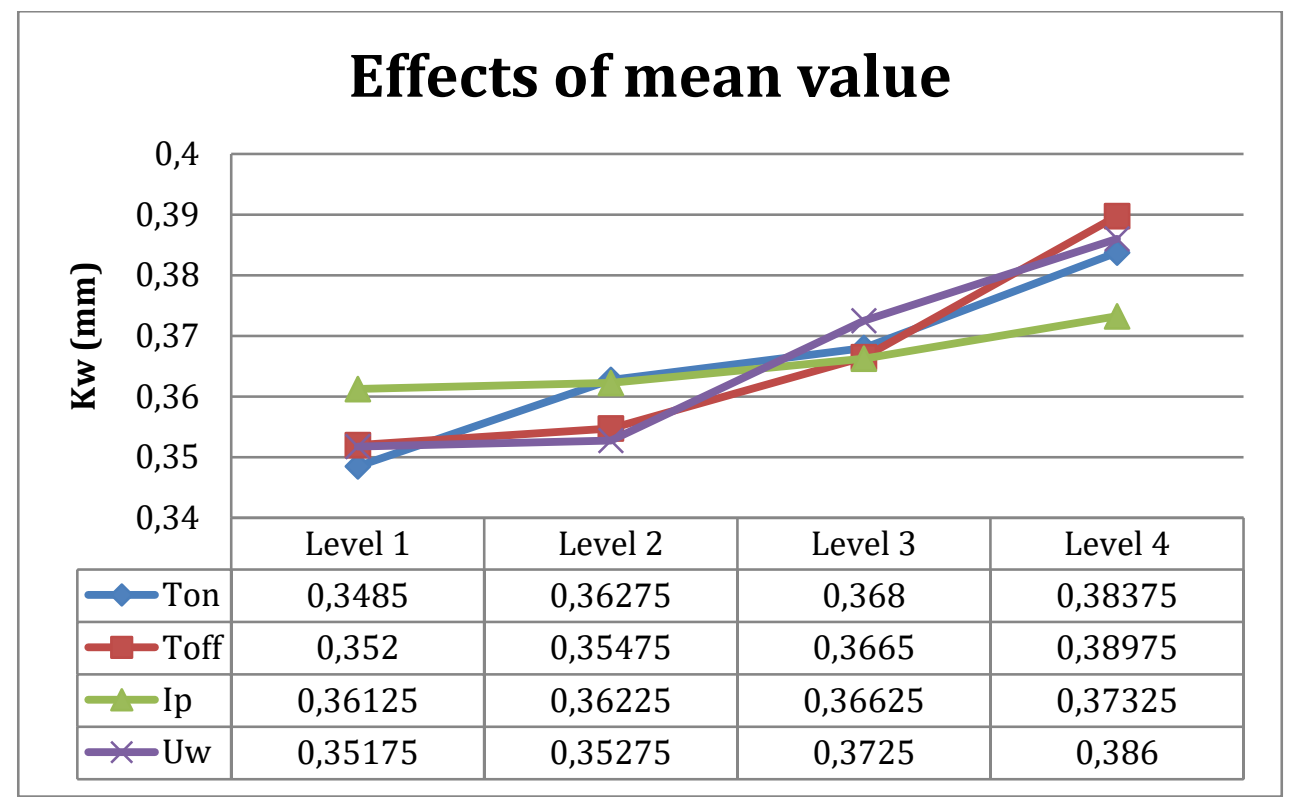

Figure 4. Effect of selected control factors at different levels for $\mathrm{K}_{\mathrm{w}}$

\subsection{Evaluation of SR}

The quality of finished surface depends on variety of the mechanical and physical characteristics of the test surface particularly, resistance to corrosion, friction, fatigue stability, and loading competency [19], [31]. Thus, the quality of surface obtained throughout the machining of test piece is interpreted by the average roughness height ( $\mathrm{Ra}$ ) and termed as surface roughness (SR). Roughness is nothing but the existence of hollows and irregular debris on finished surface as a result of spark discharges. In an effort to examine the influence of control factors, an ANOVA analysis has been conducted and results corresponding to SR depicted in Table 8. The results from ANOVA interpreted that pulse duration is the uttermost influencing factor accounting for $85.71 \%$ of contribution. Figure 5 illustrates graphs depicting the impact of control factors on SR with response values, which indicate that surface quality deteriorate with increasing in pulse duration and peak current while improves with rise in pulse interval. 
Table 8. ANOVA for SR

\begin{tabular}{|c|c|c|c|c|c|c|c|}
\hline Source & DF & Seq SS & Adj SS & Adj MS & F & P & \% \\
\hline Ton & 3 & 0.153867 & 0.153867 & 0.051289 & 288.55 & 0.000 & 85.71 \\
\hline Toff & 3 & 0.009269 & 0.009269 & 0.003090 & 17.38 & 0.021 & 5.16 \\
\hline Ip & 3 & 0.010211 & 0.010211 & 0.003404 & 19.15 & 0.018 & 5.68 \\
\hline Uw & 3 & 0.005639 & 0.005639 & 0.001880 & 10.58 & 0.042 & 3.14 \\
\hline $\begin{array}{c}\text { Residual } \\
\text { Errors }\end{array}$ & 3 & 0.000533 & 0.000533 & 0.000178 & & & \\
\hline Total & 15 & 0.179520 & & & & & \\
\hline S = 0.01333 & R-Sq $=99.7 \%$ R-Sq(adj) $=98.5 \%$ & & & \\
\hline
\end{tabular}

This may be for the reason that enough spark energy creates larger current intensity causes higher material erosion from the surface layers. The ionized particles that form, erupt and eject the material from the work surface after each pulse duration, forming wide and deep craters. The surface irregularities due to these craters lead to increase SR and also attributed that augmentation of plasma channel with rise in pulse duration [33], [34].

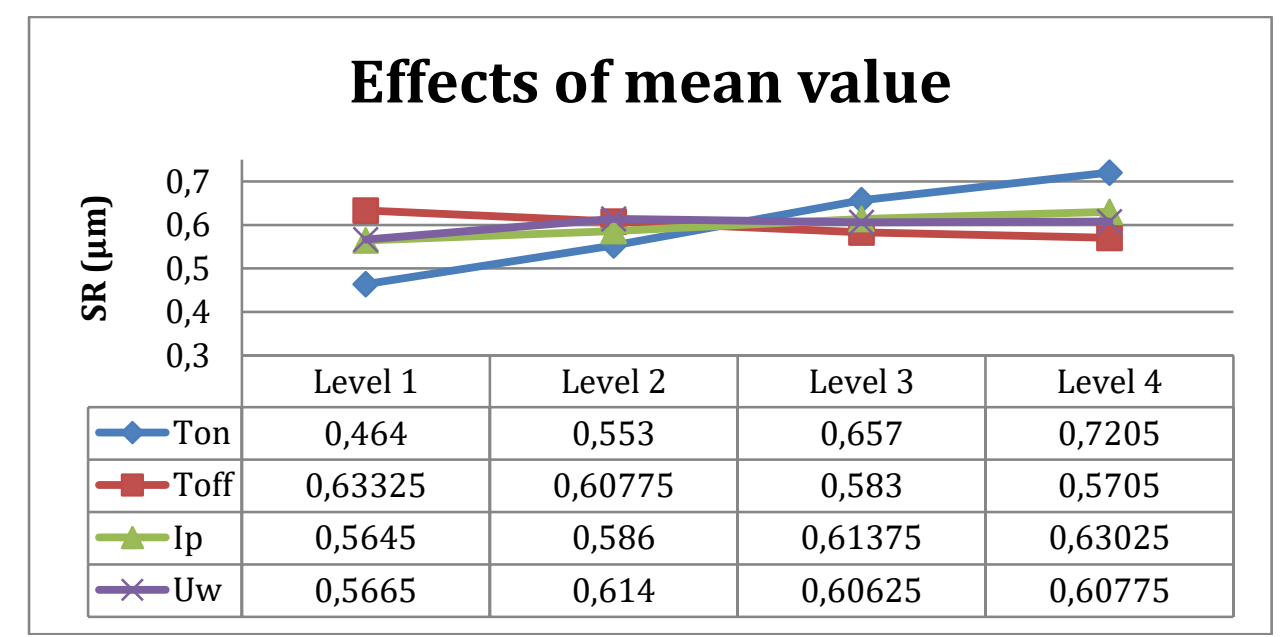

Figure 5. Effect of selected control factors at different level for SR

\subsection{Microstructure Characterization of Surface}

The EDM surface is usually tarnish in nature, consisting of a resolidified layers, craters, pockmarks, globules, debris, droplets and other layers.

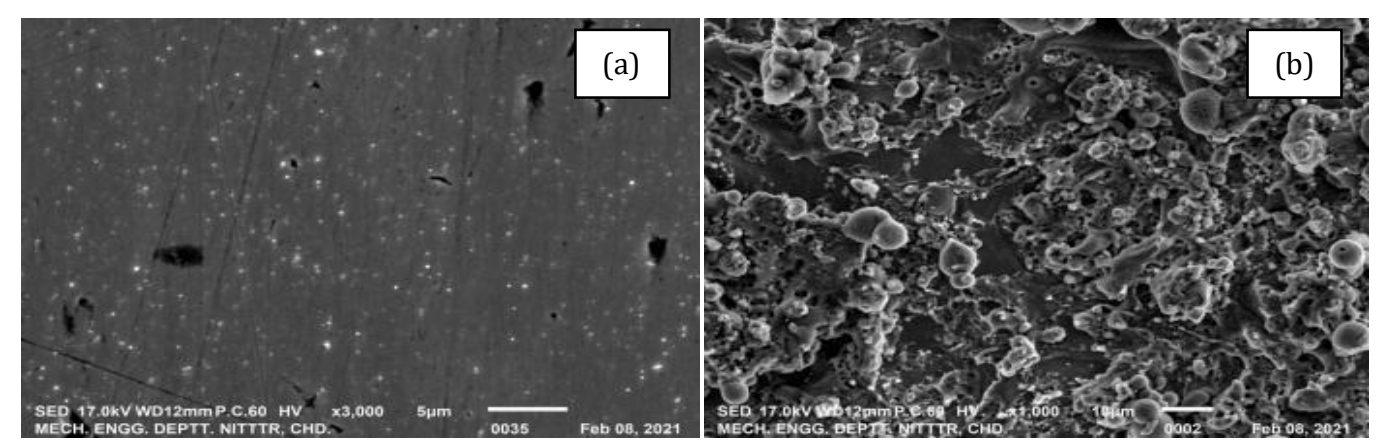

Figure 6. SEM micrograph of Inconel 718 (a) received material (b) after machining with wire EDM 
SEM analysis has been done in this study to check and evaluate the microstructure characteristics of the machined surface with different range of measurement. Figure 6(a) depicts image of the surface before the machining and Figure 6(b) after machining of Inconel 718 with wire-EDM. The surface consists of spherical grains separated from test piece which cannot be flushed out from the surface with dielectric pressure, globules of debris that melts and stick to the surface, deposits and randomly distributed craters of different sizes. These craters are nothing but a void and cavities, created by spherical chips that have broken away from the surface due to the impact of spark in between test piece and wire electrode during the machining. Owing to the release of trapped gases during the solidification, pockmarks appeared on the machined surface. Molten debris solidifies and spread as globules on the machined surface due to surface tension [35]. The SEM images of the test piece which were showing highest MRR ( $\mathrm{T}_{\mathrm{on}}=113 \mu \mathrm{s}$, $\mathrm{T}_{\text {off }}=54 \mu \mathrm{s}, \mathrm{I}_{\mathrm{p}}=11 \mathrm{~A}, \mathrm{U}_{\mathrm{w}}=4 \mathrm{~m} / \mathrm{min}$ ) depicted in Figure 7 (a) and 7 (b), lowest SR and $\mathrm{K}_{\mathrm{w}}\left(\mathrm{T}_{\mathrm{on}}=104 \mu \mathrm{s}, \mathrm{T}_{\text {off }}=50 \mu \mathrm{s}, \mathrm{I}_{\mathrm{p}}=10 \mathrm{~A}, \mathrm{U}_{\mathrm{w}}=1 \mathrm{~m} / \mathrm{min}\right)$ depicted in Figure 8(a) and $8(\mathrm{~b})$.

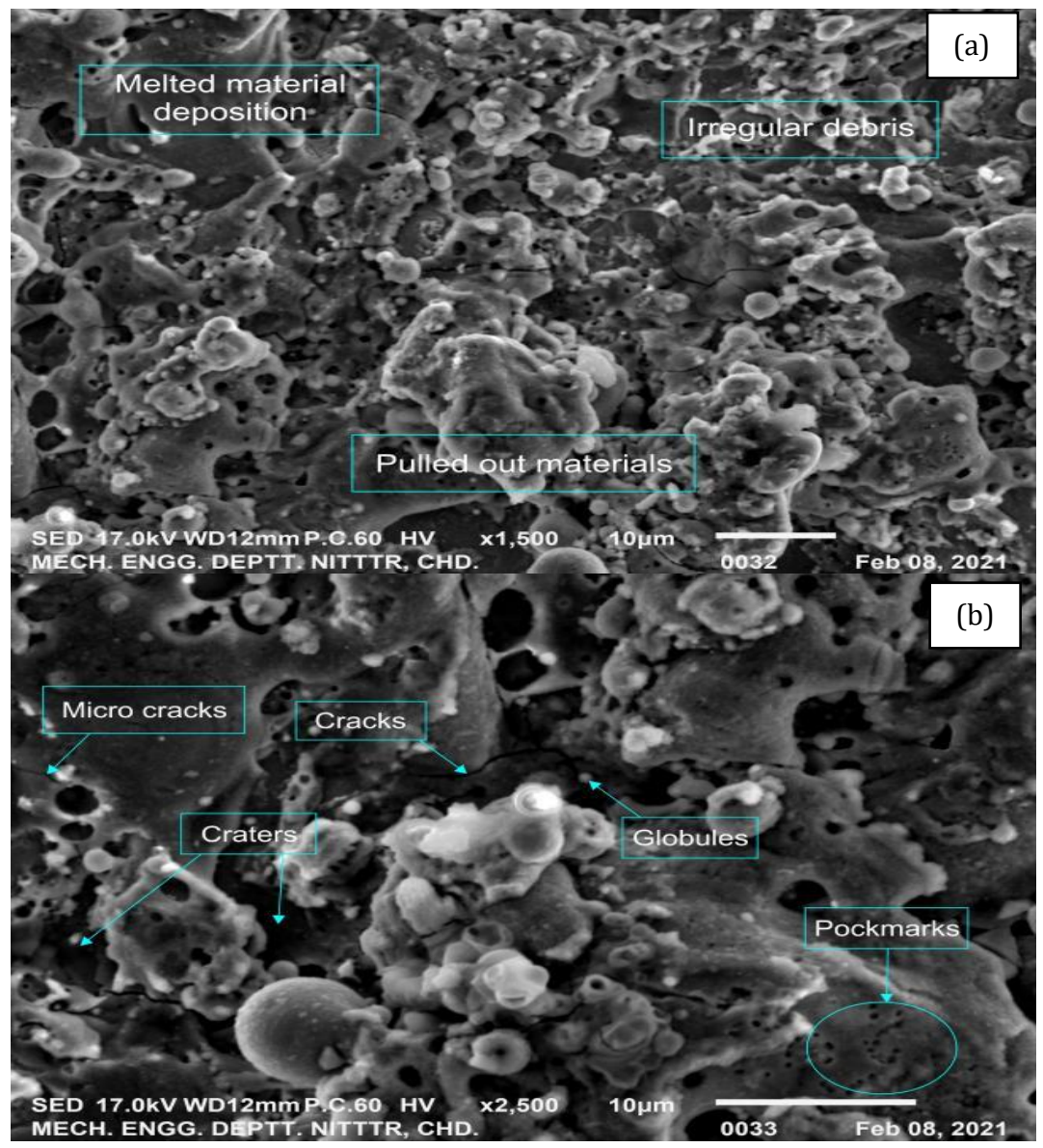

Figure 7. SEM micrographs of machined surface during wire $E D M$ for $M R R\left(T_{\text {on }}=113\right.$ $\mu \mathrm{s}, \mathrm{T}_{\text {off }}=54 \mu \mathrm{s}, \mathrm{I}_{\mathrm{p}}=11 \mathrm{~A}, \mathrm{U}_{\mathrm{w}}=4 \mathrm{~m} / \mathrm{min}$ ) showing (a) material deposition (b) pockmarks and craters 
It was perceive that at the highest value of MRR $\left(3.073 \mathrm{~mm}^{3} / \mathrm{min}\right)$, wide and deep craters has developed because of higher pulse duration (113 $\mu \mathrm{s})$ and peak current $(11 \mathrm{~A})$, depicts in Figure 7 . This may be for the reason that higher pulse duration results in high discharge energy which leads to the flow of heat towards the surface results in higher dissipation of materials from surface leading to large number of pockmarks, debris and craters [36]. During machining, de-ionized water flushes out some of the molten material and looks in a pulled out shape on the machined surface. The remaining materials re-solidified in the form of uneven or irregular debris. However, the surface had fewer craters, micro-cracks and some visible pockmarks when the minimum SR of experimental run 1 was evaluated using the SEM depicted in Figure 8. This may be for the reason that when peak current is low, less intense heat transfer towards surface and lower spark generation causes the less material extraction from the test piece that improves the surface smoothness and lower the Kw as well [23], [37], [38].

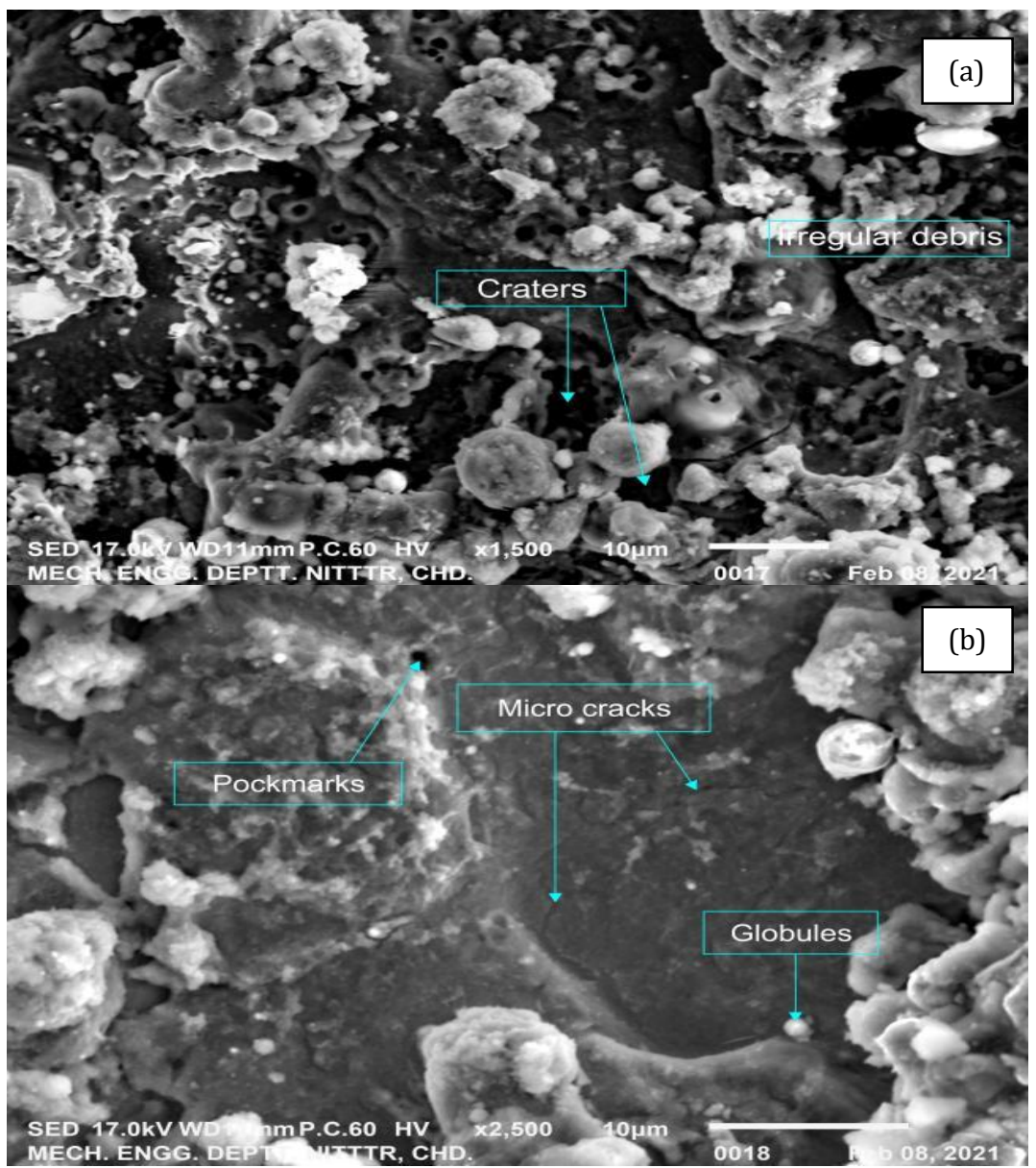

Figure 8. SEM micrographs of machined surface during wire EDM for SR and Kw $\left(\left(\mathrm{T}_{\text {on }}=104 \mu \mathrm{s}, \mathrm{T}_{\text {off }}=50 \mu \mathrm{s}, \mathrm{I}_{\mathrm{p}}=10 \mathrm{~A}, \mathrm{U}_{\mathrm{w}}=1 \mathrm{~m} / \mathrm{min}\right.\right.$ ) showing (a) Irregular debris (b) micro-cracks and globules 
The occurrence of elements on the surface of test piece analysed using EDXS analysis depicted in Figure 9(a) and 9(b), perceived that some other elements are appear on the test piece's surface apart from elements present before machining. This may be due to transfer of materials from wire electrode and dielectric fluid. Elements also appeared from the debris deposited at the surface in compounded phase.
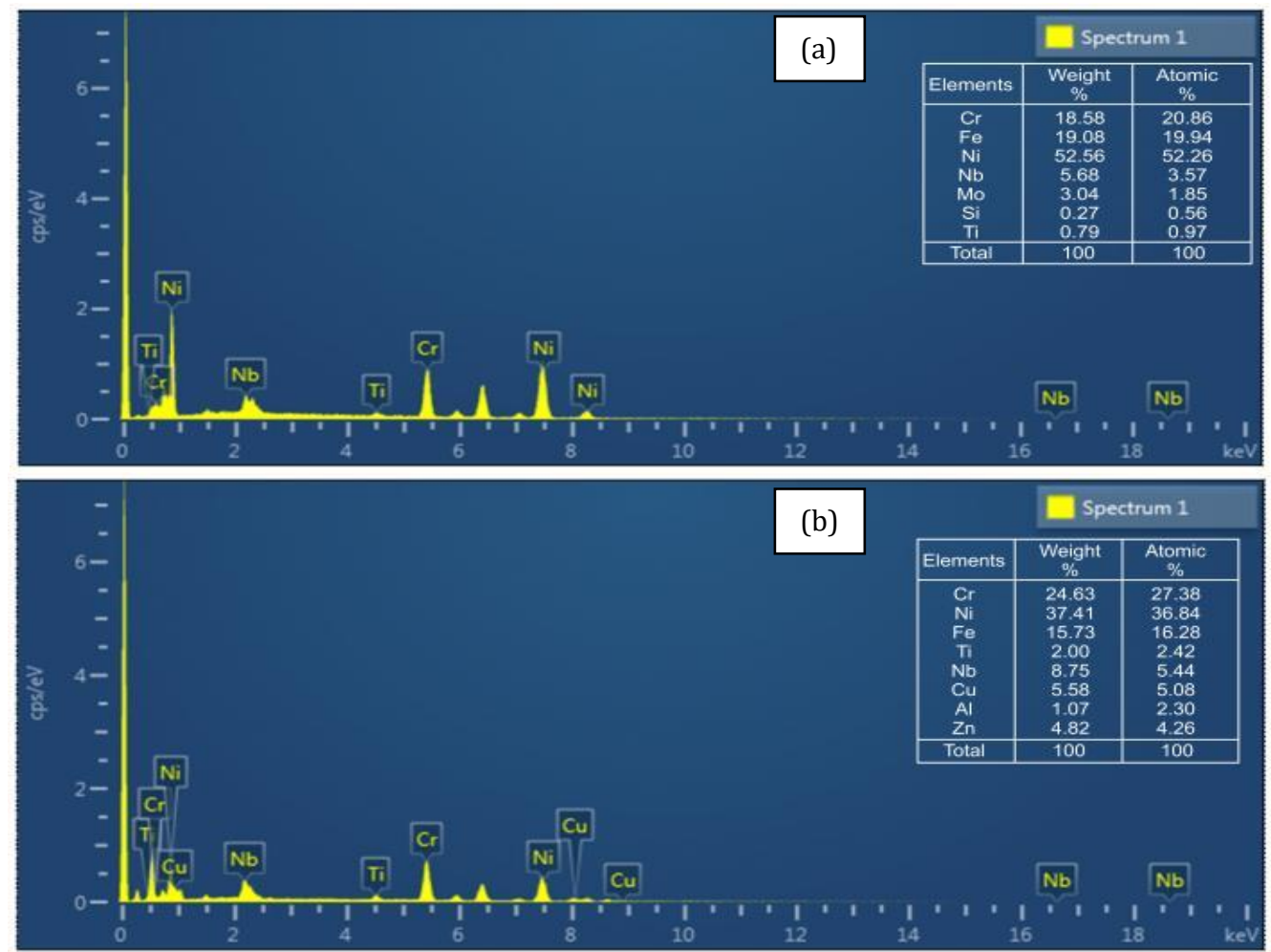

Figure 9. EDXS elemental spectrum with composition of (a) received material (b) machined surface obtained

The analysis also revealed that large number of elements transferred to surface of test piece from the wire electrode. $\mathrm{Cu}$ (Copper), $\mathrm{Zn}$ (Zinc) and $\mathrm{Al}$ (Aluminium) were located in the EDXS spectrum, suggesting that a large volume of these elements have relocated to the test piece's surface caused by decomposition of deionised water and re-solidification of electrode material at high temperature. Transfer of elements is depending on pulse duration and peak current.

\subsection{MULTI-RESPONSE OPTIMIZATION USING T-GRA}

The values of GRC and GRG for each performance measures are arranged in Table 9. GRG values are considered as the single performance and are optimized using the Taguchi's technique in Minitab(R)-16.1.1. For all experimental runs, the experiment with the maximum GRG value is considered to be the best option (out of 16 experimental run). The ranks were assigned in accordance with ascending GRG values. 
Table 9. Normalized data and values of GRC and GRG of each performance

\begin{tabular}{|c|c|c|c|c|c|c|c|c|}
\hline \multirow{2}{*}{$\begin{array}{c}\text { Exp. } \\
\text { No. }\end{array}$} & \multicolumn{3}{|c|}{ Normalized values } & \multicolumn{3}{|c|}{ GRC } & \multirow{2}{*}{ GRG } & \multirow{2}{*}{ Rank } \\
\hline 1 & MRR & Kw & SR & MRR & Kw & SR & & \\
\hline 2 & 0.000 & 1.000 & 1.000 & 0.333 & 1.000 & 1.000 & $\mathbf{0 . 7 7 8}$ & 1 \\
\hline 3 & 0.482 & 0.947 & 0.847 & 0.446 & 0.904 & 0.766 & 0.705 & 2 \\
\hline 4 & 0.834 & 0.138 & 0.847 & 0.751 & 0.367 & 0.766 & 0.628 & 3 \\
\hline 5 & 0.396 & 0.649 & 0.567 & 0.453 & 0.588 & 0.536 & 0.526 & 11 \\
\hline 6 & 0.234 & 0.457 & 0.699 & 0.395 & 0.480 & 0.624 & 0.500 & 14 \\
\hline 7 & 0.605 & 0.564 & 0.686 & 0.559 & 0.534 & 0.614 & 0.569 & 7 \\
\hline 8 & 0.699 & 0.383 & 0.675 & 0.624 & 0.448 & 0.606 & 0.559 & 9 \\
\hline 9 & 0.809 & 0.372 & 0.214 & 0.723 & 0.443 & 0.389 & 0.518 & 12 \\
\hline 10 & 0.769 & 0.415 & 0.280 & 0.684 & 0.461 & 0.410 & 0.518 & 13 \\
\hline 11 & 0.272 & 0.660 & 0.462 & 0.407 & 0.595 & 0.482 & 0.495 & 15 \\
\hline 12 & 0.670 & 0.383 & 0.575 & 0.603 & 0.448 & 0.541 & 0.530 & 10 \\
\hline 13 & 0.925 & 0.489 & 0.000 & 0.870 & 0.495 & 0.333 & 0.566 & 8 \\
\hline 14 & 0.861 & 0.574 & 0.224 & 0.782 & 0.540 & 0.392 & 0.571 & 6 \\
\hline 15 & 1.000 & 0.096 & 0.290 & 1.000 & 0.356 & 0.413 & 0.590 & 5 \\
\hline 16 & 0.727 & 0.000 & 0.346 & 0.647 & 0.333 & 0.433 & 0.471 & 16 \\
\hline
\end{tabular}

Experiment number 1 has the maximum GRG value of 0.788 and is graded first with foremost values of MRR as $1.092 \mathrm{~mm}^{3} / \mathrm{min}$; $\mathrm{Kw}$ as 0.317 $\mathrm{mm}$; and SR as $0.423 \mu \mathrm{m}$. Table 10 depicts the GRG response values for each factor along with their levels. Every response characteristic's optimum value is predicted using the impact of significant factors. The response variable values must lie in $95 \%$ confidence interval, as determined by CICE validation experiments.

Table 10. Response table for GRG

\begin{tabular}{|c|c|c|c|c|c|c|}
\hline \multirow{2}{*}{ Factors } & \multicolumn{4}{|c|}{ Levels } & \multirow{2}{*}{ Delta } & \multirow{2}{*}{ Rank } \\
\cline { 2 - 5 } & $\mathbf{1}$ & $\mathbf{2}$ & $\mathbf{3}$ & $\mathbf{4}$ & & \\
\hline $\mathrm{T}_{\text {on }}$ & $\mathbf{0 . 6 8 0 2}$ & 0.5384 & 0.5154 & 0.5496 & 0.1648 & 1 \\
\hline $\mathrm{T}_{\text {off }}$ & $\mathbf{0 . 5 9 6 9}$ & 0.5736 & 0.5658 & 0.5472 & 0.0497 & 3 \\
\hline $\mathrm{I}_{\mathrm{p}}$ & 0.5608 & $\mathbf{0 . 5 8 7 7}$ & 0.5648 & 0.5703 & 0.0269 & 4 \\
\hline $\mathrm{U}_{\mathrm{w}}$ & $\mathbf{0 . 6 1 2 1}$ & 0.5813 & 0.5312 & 0.5590 & 0.0810 & 2 \\
\hline
\end{tabular}

The predicted GRG is computed by utilising Equation 5:

$\mu=\mu_{\mathrm{r}}+\sum_{i=1}^{n}\left(\mu_{\mathrm{i}}-\mu_{\mathrm{r}}\right)$

$\mu_{r}$ is average score of GRG, $\mu_{i}$ is average score of GRG at optimum level, and $n$ control factors. Optimum values were predicted using equation and response values in a similar way to GRG.

\subsection{Confirmation test}

After predicting the optimum levels of control factors of the wire-EDM through analysis, the next effort is to confirm and substantiate the performance results using predicted values. Accordingly, the confirmation test had performed for the performance outcomes. The outcomes of the confirmatory tests are correlated with initial levels of the control factors. 
Table 11 depicts the outcomes of confirmation run for the performance measures. Two confirmation tests were effectuated to validate the performance characteristics obtained at utmost levels of control factors.

Table 11. Confirmatory experimental results

\begin{tabular}{|c|c|c|c|c|}
\hline \multirow[b]{2}{*}{$\begin{array}{l}\text { Process } \\
\text { Setting }\end{array}$} & \multirow{2}{*}{$\begin{array}{c}\text { Initial } \\
\text { optimized } \\
\text { (6 }^{\text {th }} \\
\text { experimental } \\
\text { run) }\end{array}$} & \multicolumn{2}{|c|}{ Optimum value using T-GRA } & \multirow[b]{2}{*}{$\begin{array}{l}\text { Percentage } \\
\text { Improvement }\end{array}$} \\
\hline & & $\begin{array}{l}\text { Predicted } \\
\text { Value }\end{array}$ & $\begin{array}{c}\text { Confirmatory } \\
\text { Value }\end{array}$ & \\
\hline $\begin{array}{l}\text { Optimum } \\
\text { condition }\end{array}$ & $\begin{array}{c}\mathrm{T}_{\mathrm{on}}=107, \\
\mathrm{~T}_{\mathrm{off}}=52, \mathrm{I}_{\mathrm{p}}=10, \\
\mathrm{U}_{\mathrm{w}}=4\end{array}$ & $\begin{array}{c}\mathrm{T}_{\mathrm{on}}=104 \\
\mathrm{~T}_{\text {off }}=50, \mathrm{I}_{\mathrm{p}}=11 \\
\mathrm{U}_{\mathrm{w}}=1\end{array}$ & $\begin{array}{c}\mathrm{T}_{\text {on }}=104, \\
\mathrm{~T}_{\text {off }}=50, \mathrm{I}_{\mathrm{p}}=11 \\
\mathrm{U}_{\mathrm{w}}=1\end{array}$ & \\
\hline MRR & 1.556 & 1.666 & 1.993 & 19.62 \\
\hline $\mathrm{K}_{\mathrm{W}}$ & 0.368 & 0.317 & 0.309 & 2.52 \\
\hline SR & 0.530 & 0.453 & 0.392 & 13.46 \\
\hline GRG & 0.518 & 0.763 & $\begin{array}{ll}------ \\
--1\end{array}$ & 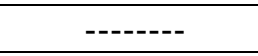 \\
\hline
\end{tabular}

The estimated value and mean value of MRR, Kw and SR acquired through the confirmation test were evaluated and compared with the $6^{\text {th }}$ experimental run from the experimental plan.

\section{CONCLUSION}

The study focuses on predicting the optimal values by adjusting the control factors of wire-EDM using Taguchi's and GRA combined approach. At first, experiments were designed using the Taguchi technique. The GRA technique converts the various values and measurements into a standard scale to obtain a single count. This count will now be useful in evaluating and assessing the multi response optimization results. The outcomes of the TGRA approach has suggested that pulse duration (104 $\mu$ s, level 1) pulse interval (50 $\mu \mathrm{s}$, level 1$)$ peak current $(11 \mathrm{~A}$, level 2$)$ wire speed $(1 \mathrm{~m} / \mathrm{min}$, level 1) exhibits the exemplary combination of control factors. Conclusively, confirmatory findings revealed that material removal rate enhanced by $19.62 \%$, improvement in kerf width by $2.52 \%$ and improvement in surface roughness by $13.46 \%$. Beside this there are some other conclusions drawn based on the findings of the experiments:

1. Peak current and pulse duration had an expressive influence on MRR. Peak current is found to be the most encouraging factor, providing 43.94 percent to MRR followed by pulse duration.

2. The pulse interval and wire speed showed expressive contribution on Kw. These significant factors should have lower levels to achieve the lower kerf.

3. With a contribution of 85.71 percent, pulse duration has a vital significance on the SR. The lower levels of pulse duration desired to attain a better surface characteristic.

4. SEM and EDXS were used to investigate the micro-structure changes, material transfer, and compound formation after machining process. SEM analysis revealed the presence of overspreading craters, several pockmarks 
of varying sizes, and diminutive cracks in the test piece. The EDXS findings confirmred the main contribution of Iron (Fe), Niobium ( $\mathrm{Nb}$ ), Nickel (Ni), Chromium $(\mathrm{Cr})$, and a minor amount of Zinc $(\mathrm{Zn})$ that is transferred to the machined surface.

5. This work can provide future experimenters and researchers with a practical guide to choose the best control factor to acquire the desired MRR, $\mathrm{K}$, and SR while using wire-EDM for Inconel 718 material.

\section{Acknowledgements}

The authors acknowledge the support of Mechanical Engineering Department, NITTTR, Chandigarh, India for conducting the SEM and EDXS analysis of the material.

\section{REFERENCES}

[1] V. Aggarwal, S. S. Khangura, and R. K. Garg, Parametric modeling and optimization for wire electrical discharge machining of Inconel 718 using response surface methodology, Int. J. Adv. Manuf. Technol., vol. 79, no. 1-4, pp. 31-47, 2015, doi: 10.1007/s00170-015-6797-8.

[2] D. Zhu, X. Zhang, and H. Ding, Tool wear characteristics in machining of nickel-based superalloys, Int. J. Mach. Tools Manuf., vol. 64, pp. 60-77, 2013, doi: 10.1016/j.ijmachtools.2012.08.001.

[3] M. Nalbant, A. Altin, and H. Gökkaya, The effect of cutting speed and cutting tool geometry on machinability properties of nickel-base Inconel 718 super alloys, Mater. Des., vol. 28, no. 4, pp. 1334-1338, 2007, doi: 10.1016/j.matdes.2005.12.008.

[4] W. Akhtar, J. Sun, P. Sun, W. Chen, and Z. Saleem, Tool wear mechanisms in the machining of Nickel based super-alloys: A review, Front. Mech. Eng., vol. 9, no. 2, pp. 106-119, 2014, doi: 10.1007/s11465-014-0301-2.

[5] S. Pervaiz, A. Rashid, I. Deiab, and M. Nicolescu, Influence of tool materials on machinability of titanium- and nickel-based alloys: $A$ review, Mater. Manuf. Process., vol. 29, no. 3, pp. 219-252, 2014, doi: 10.1080/10426914.2014.880460.

[6] M. S. Hewidy, T. A. El-Taweel, and M. F. El-Safty, Modelling the machining parameters of wire electrical discharge machining of Inconel 601 using RSM, J. Mater. Process. Technol., vol. 169, no. 2, pp. 328-336, 2005, doi: 10.1016/j.jmatprotec.2005.04.078.

[7] D. R. Unune and H. S. Mali, Experimental investigation on lowfrequency vibration assisted micro-WEDM of Inconel 718, Eng. Sci. Technol. an Int. J., vol. 20, no. 1, pp. 222-231, Feb. 2017, doi: 10.1016/j.jestch.2016.06.010.

[8] H. Payal, S. Maheshwari, and P. S. Bharti, Parametric optimization of EDM process for Inconel 825 using GRA and PCA approach, J. Inf. Optim. Sci., vol. 40, no. 2, pp. 291-307, 2019, doi: 10.1080/02522667.2019.1578090.

[9] R. Chalisgaonkar and J. Kumar, Multi-response optimization and 
modeling of trim cut WEDM operation of commercially pure titanium (CPTi) considering multiple user's preferences, Eng. Sci. Technol. an Int. J., vol. 18, no. 2, pp. 125-134, 2015, doi: 10.1016/j.jestch.2014.10.006.

[10] N. Sharma, R. Khanna, and R. D. Gupta, WEDM process variables investigation for HSLA by response surface methodology and genetic algorithm, Eng. Sci. Technol. an Int. J., vol. 18, no. 2, pp. 171177, 2015, doi: 10.1016/j.jestch.2014.11.004.

[11] M. Ehsan Asgar and A. K. Singh Singholi, Parameter study and optimization of WEDM process: A Review, in IOP Conference Series: Materials Science and Engineering, Oct. 2018, vol. 404, no. 1, doi: 10.1088/1757-899X/404/1/012007.

[12] L. Li, Z. Y. Li, X. T. Wei, and X. Cheng, Machining characteristics of inconel 718 by sinking-EDM and wire-EDM, Mater. Manuf. Process., vol. 30, no. 8, pp. 968-973, 2015, doi: 10.1080/10426914.2014.973579.

[13] M. Shabgard, S. Farzaneh, and A. Gholipoor, Investigation of the surface integrity characteristics in wire electrical discharge machining of Inconel 617, J. Brazilian Soc. Mech. Sci. Eng., vol. 39, no. 3, pp. 857-864, 2017, doi: 10.1007/s40430-016-0556-0.

[14] L. Li, Y. B. Guo, X. T. Wei, and W. Li, Surface integrity characteristics in wire-EDM of inconel 718 at different discharge energy, Procedia CIRP, vol. 6, no. May, pp. 220-225, 2013, doi: 10.1016/j.procir.2013.03.046.

[15] T. R. Newton, S. N. Melkote, T. R. Watkins, R. M. Trejo, and L. Reister, Investigation of the effect of process parameters on the formation and characteristics of recast layer in wire-EDM of Inconel 718 , Mater. Sci. Eng. A, vol. 513-514, no. C, pp. 208-215, 2009, doi: 10.1016/j.msea.2009.01.061.

[16] M. Gołąbczak, P. Maksim, P. Jacquet, A. Gołąbczak, K. Woźniak, and C. Nouveau, Investigations of geometrical structure and morphology of samples made of hard machinable materials after wire electrical discharge machining and vibro-abrasive finishing, Materwiss. Werksttech., vol. 50, no. 5, pp. 611-615, May 2019, doi: 10.1002/mawe.201800208.

[17] M. A. Mohd Zakaria, R. I. Raja Abdullah, M. S. Kasim, and M. H. Ibrahim, Enhancing the Productivity of Wire Electrical Discharge Machining Toward Sustainable Production by using Artificial Neural Network Modelling, Emit. Int. J. Eng. Technol., vol. 7, no. 1, pp. 261-274, 2019, doi: 10.24003/emitter.v7i1.365.

[18] F. Klocke, M. Schwade, A. Klink, and A. Kopp, EDM machining capabilities of magnesium (Mg) alloy WE43 for medical applications, Procedia Eng., vol. 19, pp. 190-195, 2011, doi: 10.1016/j.proeng.2011.11.100.

[19] A. Mostafapor and H. Vahedi, Wire electrical discharge machining of 
AZ91 magnesium alloy; Investigation of effect of process input parameters on performance characteristics, Eng. Res. Express, vol. 1, no. 1, Sep. 2019, doi: 10.1088/2631-8695/ab26c8.

[20] A. P. Markopoulos, E.-L. Papazoglou, and P. Karmiris-Obratański, Experimental Study on the Influence of Machining Conditions on the Quality of Electrical Discharge Machined Surfaces of aluminum alloy Al5052, Machines, vol. 8, no. 1, p. 12, 2020, doi: 10.3390/machines8010012.

[21] T. Babu Rao and A. Gopala Krishna, Simultaneous optimization of multiple performance characteristics in WEDM for machining ZC63/SiCp MMC, Adv. Manuf., vol. 1, no. 3, pp. 265-275, 2013, doi: 10.1007/s40436-013-0029-y.

[22] R. Bobbili, V. Madhu, and A. K. Gogia, Modelling and analysis of material removal rate and surface roughness in wire-cut EDM of armour materials, Eng. Sci. Technol. an Int. J., vol. 18, no. 4, pp. 664668, 2015, doi: 10.1016/j.jestch.2015.03.014.

[23] R. Bobbili, V. Madhu, and A. K. Gogia, Multi response optimization of wire-EDM process parameters of ballistic grade aluminium alloy, Eng. Sci. Technol. an Int. J., vol. 18, no. 4, pp. 720-726, 2015, doi: 10.1016/j.jestch.2015.05.004.

[24] S. Banerjee, B. Panja, and S. Mitra, Effect of process parameters on machining EN 47 spring steel through WEDM, Emerg. Mater. Res., vol. 9, no. 3, pp. 628-636, 2020, doi: 10.1680/jemmr.19.00075.

[25] S. Evran, Surface roughness and material removal rate analyses of hard copper alloy in wire electrical discharge machining, Emerg. Mater. Res., vol. 9, no. 3, pp. 730-737, 2020, doi: 10.1680/jemmr.20.00088.

[26] G. Veda Prakash et al., Comparative study of electrical breakdown properties of deionized water and heavy water under pulsed power conditions, Rev. Sci. Instrum., vol. 87, no. 1, 2016, doi: 10.1063/1.4940420.

[27] D. Julong, Introduction to grey systems theory, J. grey Syst. 1, pp. 124, 1989.

[28] A. N. Siddiquee, Z. A. Khan, and Z. Mallick, Grey relational analysis coupled with principal component analysis for optimisation design of the process parameters in in-feed centreless cylindrical grinding, Int. J. Adv. Manuf. Technol., vol. 46, no. 9-12, pp. 983-992, 2010, doi: 10.1007/s00170-009-2159-8.

[29] V. Kumar. S and P. Kumar. M, Optimization of cryogenic cooled EDM process parameters using grey relational analysis, J. Mech. Sci. Technol., vol. 28, no. 9, pp. 3777-3784, 2014, doi: 10.1007/s12206014-0840-9.

[30] V. Srivastava and P. M. Pandey, Effect of process parameters on the performance of EDM process with ultrasonic assisted cryogenically cooled electrode, J. Manuf. Process., vol. 14, no. 3, pp. 
393-402, 2012, doi: 10.1016/j.jmapro.2012.05.001.

[31] S. Dzionk and M. S. Siemiatkowski, Studying the effect of working conditions on WEDM machining performance of super alloy inconel 617, Machines, vol. 8, no. 3, Sep. 2020, doi: 10.3390/MACHINES8030054.

[32] K. P. Somashekhar, N. Ramachandran, and J. Mathew, Material removal characteristics of microslot (kerf) geometry in $\boldsymbol{\mu}$-WEDM on aluminum, Int. J. Adv. Manuf. Technol., vol. 51, no. 5-8, pp. 611-626, 2010, doi: 10.1007/s00170-010-2645-z.

[33] P. C. Pandey and S. T. Jilani, Plasma channel growth and the resolidified layer in edm, Precis. Eng., vol. 8, no. 2, pp. 104-110, 1986, doi: 10.1016/0141-6359(86)90093-0.

[34] A. Goyal, Investigation of material removal rate and surface roughness during wire electrical discharge machining (WEDM) of Inconel 625 super alloy by cryogenic treated tool electrode, J. King Saud Univ. - Sci., vol. 29, no. 4, pp. 528-535, Oct. 2017, doi: 10.1016/j.jksus.2017.06.005.

[35] T. Jadam, S. K. Sahu, S. Datta, and M. Masanta, EDM performance of Inconel 718 superalloy: application of multi-walled carbon nanotube (MWCNT) added dielectric media, J. Brazilian Soc. Mech. Sci. Eng., vol. 41, no. 8, 2019, doi: 10.1007/s40430-019-1813-9.

[36] P. Kumar, M. Gupta, and V. Kumar, Surface integrity analysis of WEDMed specimen of Inconel 825 superalloy, Int. J. Data Netw. Sci., vol. 2, pp. 79-88, 2018, doi: 10.5267/j.ijdns.2018.8.001.

[37] M. E. Asgar and A. K. S. Singholi, Study of the Effect of Dielectric on Performance Measure in EDM, Lect. Notes Mech. Eng., pp. 843-850, 2021, doi: 10.1007/978-981-33-4320-7_75.

[38] P. Kumar, M. Gupta, and V. Kumar, Microstructural analysis and multi response optimization of WEDM of Inconel 825 using RSM based desirability approach, J. Mech. Behav. Mater., vol. 28, no. 1, pp. 39-61, 2019, doi: 10.1515/jmbm-2019-0006. 